\title{
Um paralelo entre os impactos das usinas hidrelétricas e termoelétricas
}

\section{$\star$ Sinclair Mallet-Guy Guerra \\ Antomar Viegas de Carvalho}
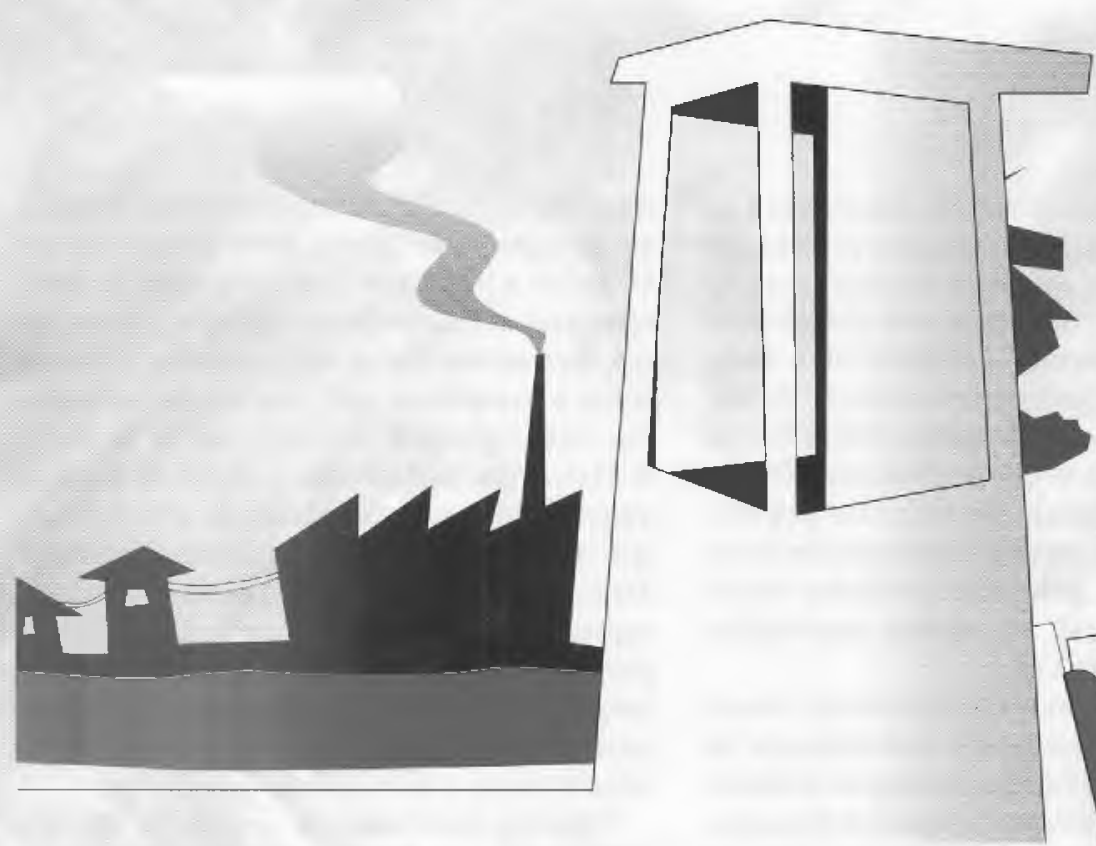

PALAVRAS-CHAVE:

meio ambiente, energia, geraçāo termoelétrica, geração hidrelétrica, qualidade de vida, matriz de impactos ambientais, matriz de Leopold.

KEY WORDS:

environment, energy, thermoelectric generation, hydroelectric generation, life quality, environmental impact matrix model, Leopold matrix.

$\star$ Professor Doutor do Departamento de Energia da Faculdade de Engenhariá Mecânica da UNICAMP.

†r Geógrafo Especialisła em Meio Ambiente e Mestrando do Departamento de Energia da Faculdade de Engenharia Mecânica da UNICAMP. 


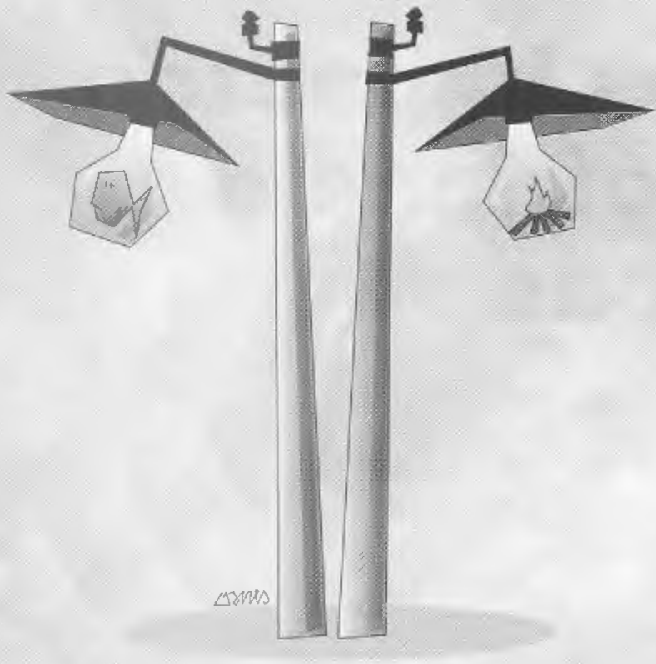

\title{
Paralelo entre os impactos ambientais das usinas hidrelétricas e termoelétricas demonstra a importância dos programas de conservação de energia.
}

\author{
Comparison between the environmental impacts \\ from the hydroelectric and thermoelectric dams \\ shows the importance of the energy conservation \\ programs.
}

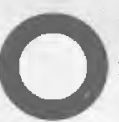

s efeitos ambientais decorrentes da implantação de grandes projetos de geração de energia elétrica em território brasileiro têm sido objeto de grande controvérsia. Neste artigo, em particular, serão analisados os impactos provocados pela implantação e operação de usinas hidrelétricas e termoelétricas e as conseqüências sobre os padrões de qualidade de vida das populaçōes, em razão da grande importância atualmente atribuida, pelas comunidades nacional e internacional, aos efeitos produzidos pela liberação do $\mathrm{CO}_{2}$

Enquanto essa preocupação cresce, conseqüências ambientalmente indesejáveis da implantaçăo das' grandes barragens hidrelétricas têm merecido preocupaçōes menores. Estas, nuuitas vezes, estão voltadas para aspectos de importância secundária quando analisadas à luz dos contextos regionais.

Os impactos ambientais das barragens hidrelétricas, contrariamente aos das emissóes de $\mathrm{CO}_{2}$, comuns à geraçāo termoelétrica convencional, restrigem-se em grande parte às regiões nas quais se localizam o empreendimento. Além dessa característica, também estas outras concorrem para que se tornem reduzidos a participação comunitária e o entendimento da questão por parte da opiniáo pública internacional: o nivel socioeconômico das regiōes, sobretudo nas áreas atingidas; a baixa capacidade de organização e de crítica e representaçāo de grande parte da populaçăo atingida, junto às esferas superiores de decisão, e as dificuldades de acesso a sistemas eficientes de informação e divulgação.

A verdadeira dimensão dos impactos sobre essas comunidades e seus reflexos a médio ou longo prazo tende, assim, a ser mini- mizada. Portanto, os aspectos mais nocivos da geraçāo hidrelétrica permanecem ainda voltados a impactos que, em última análise, apresentam interferências globais, por menores que sejam. Estes referem-se aos danos sobre a camada de ozônio e ao efeito estufa, em conseqüência da geração de metano ( $\left.\mathrm{CH}_{4}\right)$, oriundo da decomposição da matéria vegetal existente nas bacias de acumulação dos reservatórios e da inundação de grandes áreas florestais. Este último efeito destaca-se especialmente pelo que representa quanto à perda do potencial de absorçấo do $\mathrm{CO}_{2}$, fato inegavelmente menor quando confrontado com as conseqüências nocivas sobre os ecossistemas naturais, então degradados.

Quando objetivamente se estabelecem procedimentos que impliquem a busca contínua da melhoria geral da qualidade de vida de toda a população, os impactos decorrentes da geraçāo elétrica devem merecer destaque compatível não só com a magnitude de seus efeitos sobre os habitantes das áreas diretamente atingidas mas também com os reflexos que promovem sobre toda a regiáo de influência. Desse modo, evitam-se falsas noçōes que, a priori, procuram classificar empreendimentos hidrelétricos como ambientalmente mais adequados. Nesse sentido, 0 termo poluição deve ser entendido de modo a abranger também os aspectos referentes à degradaçāo das condiçōes ambientais, quandọ da instalação e operação de empreendimentos que, por sua dimensão ou natureza, entrem em conflito com as características ambientais da região na qual se inserem. Essa abordagem opōe-se àquela que relaciona a poluição apenas à degradação das propriedades físico-químicas dos elementos. 
Sob essa ótica, propōe-se o estudo pormenorizado de todas as alteraçốes ambientais promovidas sobre os meios físico, biológico e antrópico. Nesse estudo, devem estâr rigorosamente contemplados todos os efeitos diretos e indiretos - e sua real interferência sobre a qualidade de vida dos habitantes tanto da atual geraçāo quanto das futuras, $\mathrm{Ca}$ bem ainda consideraçōes relativas à oportunidade de empreendimentos e a sua prioridade no contexto social dos respectivos países. Isto porque os elevados custos desses projetos, socialmente distribuídos, guardam pouca relação quando se trata do aproveitamento de seus benefícios. Assim, muitas vezes implantados para viabilizar setores eletrointensivos, acarretam, aos países, grande endividamento, com sérias conseqüências sobre a capacidade nacional de investimentos sociais.

Ao se avaliarem ambientalmente os grandes projetos hidrelétricos no Terceiro Mundo, faz-se necessário, portanto, um debate mais profundo, de modo a que se relativizem, a partir do contexto regional, os impactos globais.

Para fins deste trabalho, que pretende facilitar a compreensão das questōes ambientais envolvidas na implantação de grandes projetos de geraçāo elétrica, será utilizada uma adaptação da matriz de avaliaçâo de impactos formulada em estudos desenvolvidos por Singer ${ }^{1}$, com base no método de Léopold ${ }^{2}$. Como será visto adiante, a razão da utilização deste metódo reside muito mais na sua facilidade de encaminhamento de análises do que no mérito de sua fundamentação conceitual.

\section{SOBRE AS METODOLOGIAS DE AVALIAÇĀO DE IMPACTOS}

Embora já tenham sido desenvolvidas diversas metodologias de AIA (Avaliação de Impacto Ambiental), ainda nāo há uma completamente aceita como base de avaliaçâo, onde sejam expressamente relacionados todos os elementos envolvidos (ver quadro 1).

Cada um dos métodos citados no quadro 1 apresenta suas vantagens e seus pontos críticos. Isso ocorre a tal ponto que muitos dos métodos sāo somente aplicados em análise específicas. $O$ quadro 1 representa uma contributução dos autores no sentido de estabelecer uma primeira ordenação da tipologia das várias metodologias de avaliaçăo de impactos, a partir de levantamentos de "estados da arte" efetuados.

Somente à guisa de exemplo, procurando demonstrar o quanto é incompleta a utiliza- ção de uma só abordagem, será tomado como referência o método de Leopold. Esse, tem por base dois aspectos fundamentais: 1. a grandeza de um impacto, avaliada em termos absolutos, e 2. sua importância; esta pode ser avaliada a partir da intensidade dos efeitos do impacto.

Ocorre, no entanto, um alto grau de subjetividade na avaliaçāo dos impactos ao se utilizar esse método, uma vez que para cada um dos impactos se faz necessária a atribuição de uma "nota" variando entre 1 (um) e 10 (dez). A partir dessas "notas" é encontrada uma média final concernente aos impactos.

O método de Leopold, utilizado neste trabalho, foi estabelecido em 1971, tendo sofrido algumas restriçōes levantadas por Bolea ${ }^{3}$. Sem dúvida alguma, cabe a questāo a ser respondida com relação sobre a oportunidade de, ainda hoje, se apresentar alguns métodos que já sofreram etapas de aperfeiçoamento. Todavia, conforme já mencionado, $\mathrm{o}$ objetivo aqui é facilitar a compreensão dos impactos provocados por empreendimentos de geração hidrelétrica e termoelétrica e nāo a aplicaçăo a um caso específico.

Nesse sentido, será apresentada uma adaptação da matriz de avaliação de impactos forrmulada em estudos desenvolvidos por Singer ${ }^{4}$. Esse autor criou, em seu trabalho, uma matriz com alguma influência da de Leopold. Tal afirmaçāo decorre do fato de que há uma atribuição de "notas" aos vários eventos que dão origem aos impactos.

A adaptação efetuada neste trabalho levou em consideração a necessidade de adequar a matriz utilizada aos objetivos como seráo descritos adiante.

\section{PREMISSAS BÁSICAS PARA A CRIAÇĀO DA MATRIZ DE IMPACTOS AMBIENTAIS}

Com o objetivo de representar com clareza e de forma integrada a magnitude das interferências ambientais resultantes dos empreendimentos termoelétricos convencionais
1. SINGER, E, da M. Metodologia para avaliação dos im. pactos ambientais da mineração. In: Anais do Encontro sobre Mineração o Meio Ambiente no Estado de São Pau10. Săo Paulo: ABGE, 1985 , p. $10-20$.

2.LEOPOLD, L. B. et al. A procedure for evaluating environmental impact. Washington DC: US Geological Service, 1971.

3. BOLEA, M. T. E. Las evaluaciones de impacto ambiental. Madrid: CIFCA, 1977.

4. SINGER, E. da M. Op. cit. 
e hidrelétricos, foi definida matriz de impactos específica. Para sua elaboração, partiu-se de premissas tais como a da necessidade de possibilitar um rápido entendimento da vasta gama de variáveis existentes; da constataçāo de como se articulam entre si e, finalmente, de suas conseqüências sobre o bemestar social.

De inicio optou-se pela separação das etapas de implantação e operação dos empreendimentos, um procedimento que se mostrou necessário, em vista, sobretudo, das características próprias de cada uma das variáveis que envolvem as etapas do processo de produçāo energética.

Portanto, ainda que os efeitos sobre o ambiente fossem, no decorrer das etapas, da mesma natureza ou composiçáo, em grande parte dos casos apresentaram, em cada uma delas, pesos e magnitudes distintas, justificando a análise em separado para a implantação e operação do empreendimento.

A opção por abordá-las em planilhas separadas deve-se, ainda, ao destaque prioritário dos efeitos da tecnologia empregada em. uma mesma etapa. Por exemplo, na etapa de implantação do empreendimento, uma hidrelétrica provoca mais prejuízo à fauna do que aquele observado na implantação de uma termoelétrica. Logo, demonstrou-se mais apropriada a aplicação das duas tecnologias na mesma planilha.

Dessa forma, obteve-se uma planilha de implantação e uma outra, de operação dos empreendimentos, com cada uma delas contendo, para cada tecnologia, os impactos e efeitos ambientais e suas conseqüências sobre a qualidade de vida das populaçốes.

No que se refere às quantificações, estas foram agregadas em três niveis de grandeza - fraco, moderado e forte -, sendo, para tanto, considerados modelos usualmente implantados no território brasileiro.

Essa composição, enibora apresentando razoável grau de generalização, nāo suscitou grandes discrepâncias da realidade, sobretudo quando se considera o caráter preliminar e de síntese do presente trabalho.

Assim, da sobreposição das duas planilhas, pode-se aferir o grau de interferência ambiental de cada tecnologia nas duas fases estudadas. Este procedimento permite, preliminarmente, a observação da presença marcante dos projetos hidrelétricos, nas várias situaçóes de prejuízo à vida das populações residentes nas áreas de interferência direta dos empreendimentos.

Ainda que os efeitos de caráter global apresentem sensivel importância nas usinas termoelétricas (UTEs), a presença contínua de aspectos deletérios ao ambiente nas usinas hidrelétricas (UHEs), suscita, no mínimo, a necessidade de estudos mais aprofundados. É somente por este meio que se pode chegar à afirmação de que os projetos hidrelétricos podem conduzir, sistematicamente, a menores interferências sobre o meio ambiente.

\section{IMPACTOS SOBRE O MEIO FÍSICO}

\section{Geologia/geomorfologia}

Desde os primeiros momentos do represamento, dependendo da área objeto da intervençăo, há possibilidades de desencadeamento do processo de acomodaçāo geológica, produzindo-se ocorrências sísmicas. Considerando que a estrutura geológica presente em grande parte do território brasileiro é constituída por maciços antigos, seu grau de suscetibilidade é, nesse caso, satisfatório. No entanto, são comuns efeitos de segunda ordem sobre a geomorfologia e solos, tais como fraturas, rupturas e escorregamentos, intensificação dos processos erosivos, aparecimento de ravina e voçorocas, assoreamento e indisponibilidade do aproveitamento de recursos minerais potencialmente existentes nas áreas afetadas. Para as usinas termoelétricas, conquanto de dimensões menos significativas, pode-se destacar a destruição e degradação ambiental nas regiōes produtoras de carvão. Nestas, os impactos geralmente apresentam grande magnitude e voltamse especialmente aos efeitos sobre o solo, vegetação e paisagem, em correspondência direta com os métodos - predatórios ou não - empregados na extração mineral.

Os impactos nesta variável, portanto, foram considerados, nas UHEs, elevados tanto em sua implantação como em sua operação, enquanto nas UTEs foram avaliados como baixos na implantação e fortes na operação.

\section{Hidrologia/hidrogeologia}

Näo obstante a alteração do curso principal de água, que passa do regime lótico para o lêntico - neste caso, com tempo de permanência infinitamente superior ao do anteriore, portanto, provocando fortes alterações em toda a bacia hidrográfica - , a formaçāo dos reservatórios hidrelétricos acarreta também alteraçōes nos regimes de montante. Elevamse acentuadamente os níveis dos lençóis subterrâneos, ao mesmo tempo que diminuem as velocidades dos tributários, produzindo, sob o ângulo apenas da ótica do meio físico, o aumento da evapotranspiraçāo potencial e comprometimento da qualidade da água. 
Estes aspectos acabam por desencadear amplo processo de reaconodação do sistema. Seus efeitos sobre o microclima, o meio biológico e também o socioeconômico serão abordados adiante ${ }^{5}$.

Nas UTEs observam-se também, embora de forma menos intensa que na UHEs, algumas implicações ambientais: o comprometimento dos corpos de água, devido à emissão de efluentes líquidos; a reduçāo da disponibilidade e da qualidade da ấgua, devido à captação para o sistema de resfriamento e geraçāo, e a elevaçâo da acidez da água e assoreamento de cursos de água, quando da extração mineral.

A expressão observada nas matrizes aponta níveis de impacto elevados na implantação e operaçẫo da UHEs, porém moderados, sobretudo em funçāo das possibilidades de controle ambiental, na operação das UTEs, e fraco em sua implantação.

\section{Clima}

Decorrência natural das transformações geomorfológicas e hidrológicas, além das impostas à vegetaçāo, as alterações climáticas têm a propriedade de provocar reflexos do projeto em regióes distantes daquela do objeto de intervenção, alterando características como o perfil do vento, temperaturas, componentes de balanço hídrico e nebulosidade.

É certo que tais interferências mantêm relaçāo direta nāo só com as dimensões do empreendimento mas também com suas características e alternativas de inserção regional.

No caso da hidrelétrica, o clima constituise em um dos efeitos de caráter global do sistema, mas sua importância será sempre reduzida quando em contraste com os efeitos inerentes à produção termoelétrica.

É exatamente neste item que se constatam os principais efeitos decorrentes da geração termoelétrica, com destaque para as emissóes de gases e material particulado na atmosfera. Nesse sentido, destaca-se a polêmica internacional sobre as possíveis mudanças climáticas acarretadas pelos gases de efeito estufa e as conseqüentes negociaçōes, em curso, sobre medidas de controle da emissão de $\mathrm{CO} 2$.

Assim, pesquisadores avançam continuamente na busca da determinação da potencialidade dos efeitos dessas emissóes, destacando, dentre estes, a elevação da temperatura média do planeta, com o degelo parcial das calotas polares, e a elevação dos níveis dos oceanos.

A valoraçăo aplicada à matriz apontou pontos fracos na implantação das UTEs, porém fortes em sua operação, já que, além dos efeitos ambientais aqui citados, implica outros, igualmente graves. Por isso, nāo obstante efeitos decorrentes de outras variáveis ambientais, o clima representa aspecto determinante na viabilizaçăo, em termos ambientais, de empreendimentos termoelétricos.

\section{IMPACTOS SOBRE O MEIO BIOLÓGICO}

\section{Fauna}

Os impactos sobre a fauna - aqui entendida como conjunto das espécies terrestres, aladas e ictícias - originam-se da destruição dos ecossistemas. Além da morte de indivíduos de várias espécies, provocada pela instalação do empreendimento, há também a agressāo a suas condiçōes de abrigo, alimentaçāo e reprodução, com uma degradação potencial muito superior à dos efeitos diretos observados na área do empreendimento.

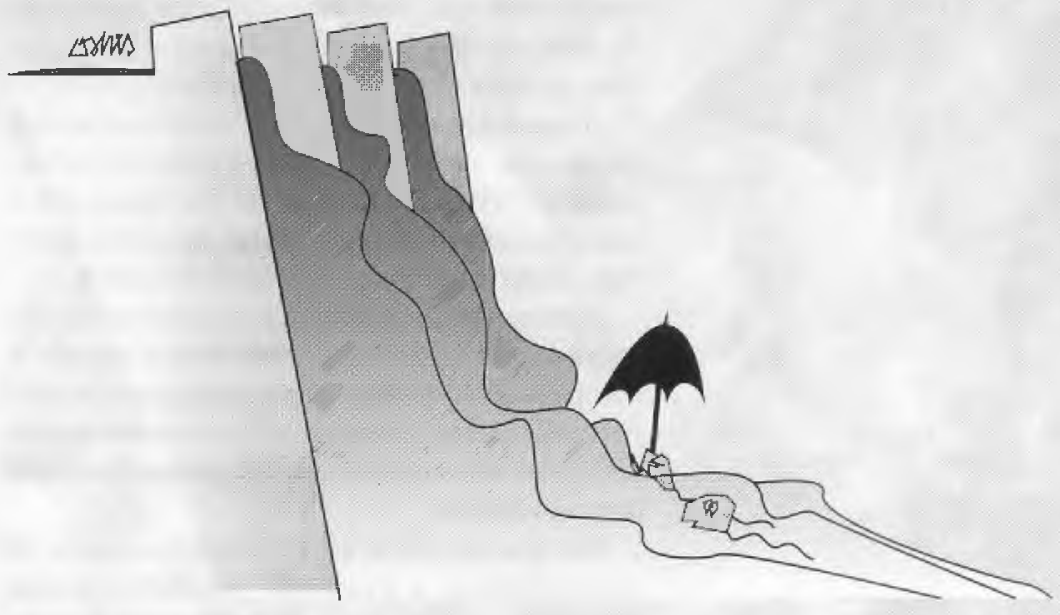

Também como conseqüência dessa situaçāo, o inexorável rompimento da cadeia alimentar não apenas provocará a mortandade de outras espécies - algumas das quais, com hábitat fora da área do projeto - como também poderá afetar, além do próprio homem, espécies da flora. O homem, embora não afetado diretamente, sofre pela proliferação de pragas e doenças junto a seus rebanhos ou lavouras.

Aqui há mais um aspecto que merece grande destaque na relação dos impactos ambientais, sendo, atualmente, objeto de amplos debates: o comprometimento da biodiversidade. Além da extinçáo de espécies conhecidas, com processo evolutivo resultante de milhares de anos, outras, sequer identificadas pela ciência, sāo colocadas em processo de extinção. Por outro lado, a ruptura de todo o
5. BRANCO, S. M. Poluição, proteção e usos múltiplos de represas. São Paulo: Edgard Blucher, 1977. 
processo resulta no comprometimento evolutivo de novas espécies, cujos benefícios à humanidade šăo completamente intangiveis.

Nas Ư'TEs, têm-se, usualmente, lesões sobre a fauna, quer pela emissão de gases nocivos e material particulado, quer pela degradação imposta às matas e à qualidade da água, porém com efeitos certamente mais localizados, e menos intensos, que os encontrados na UHE. Portanto, definiram-se como fracos os efeitos da implantaçáo das UTEs, e moderados em sua operaçāo. Para as hidrelétricas, estabeleceram-se os limites máximos, tanto para implantação como para operaçāo dos sistemas.

\section{Flora}

Inserida também na questão da biodiversidade, a flora é igualmente impactada pela formação dos reservatórios, e, como já mencionado, também pelas UTEs.

Embora merecedores de maior destaque internacional, sobretudo em razão dos efeitos globais que sua degradaçāo suscita, são de elevada magnitude os impactos provocados, no nível local, em razâo da degradaçāo da flora. Estes atingem desde a aceleração dos processos erosivos e suas conseqüências, como a perda da qualidade da água, até o comprometimento do hábitat de várias espécies, desencadeando efeitos já descritos.

Nesses itens, ainda que a graduação observada nas matrizes aponte fortes impactos na operação das duas formas de geraçāo elétrica, devem ser consideradas maiores possibilidades de controle nos empreendimentos termoelétricos.

No que se refere à implantaçāo, coube às termoelétricas a avaliação de efeitos fracos enquanto que, para as hidrelétricas, foram, mais uma vez, definidos como fortes.

\section{MEID SOCIOECONÔMICO}

\section{Dinâmica populacional}

A implantação das hidrelétricas não raramente impōe a necessidade de remoção e reassentamento de núcleos urbanos, ribeirinhos e da populaçăo isolada. Isto apresenta graves dificuldades a esses habitantes, cujas consequiências extrapolam a simples noção de sobrevivência, chegando a exercer interferências de caráter psicossocial.

Por outro lado, são consideráveis os efeìtos resultantes do grande afluxo de pessoas direta ou indiretamente necessárias para a realização das obras. Ao sobrecarregarem a infra-estrutura existente comprometem seus serviços, e como este afluxo fica restrito aó perîodo das obras, nāo ocorrem melhorias, já que eventuais investimentos com seu redimensionamento seguramente tornar-seiam ociosos ao término das obras.

Nas termoelétricas, dadas as características mais moderadas das dimensões do empreendimento, tais efeitos são minimizados. No entanto, destacam-se, para as populaçōes locais, os riscos em funçâo dos vazamentos dos oleodutos, além de prejuízos à saúde pública, com doenças respiratórias ou dermatológicas causadas pela emissão de poluentes aéreos (SO2/NOx/Material Particulado).

Os efeitos deletérios foram considerados fortes na implantaçāo das UHĔs e moderados nas UTEs. Nos procedimentos de operação foram considerados moderados apenas nos empreendimentos hidrelétricos e fortes para as termoelétricas.

\section{Alteração da organização espacial da região}

A inundação da infra-estrutura regional, quando atingidas as estradas, pontes, núcleos urbanos, rede elétrica e telefônica, e mais a desatirculação das atividades econômicas produzem o rompimento da estrutura pela qual se organiza o espaço regional e toda a hierarquia urbana.

Os reflexos desse fato sobre a regiäo objeto da intervençāo podem assumir variadas formas, desde alterações nas vocaçōes regionais até seu colapso, fazendo com que essa regiāo possa vir a tornar-se "zona de repulsāo populacional". Nas UTEs, por sua vez, os efeitos dessa ordem são muito raros e, quando ocorrem, estāo associados a outros fatores. No entanto, salientamos os prejuízos nas lavouras de consumo in natura, com a possibilidade de ocorrência de chuva ácida, de prejuízo ou inviabilidade de atividades pecuárias e de prejuízo às atividades pesqueiras e turísticas, aspectos estes mais uma vez ligados à emissões de poluentes.

Assim, para as UT'Es, ficou determinada fraca magnitude na implantação, e moderada na operaçāo do empreendimento. Para as UHEs, determinou-se forte magnitude para a implantaçāo, e moderada para a operação, visto que aspectos como o aproveitamento do potencial tứístico decorrente de formação de reservatórios, raramente utilizados em sua plenitude, podem mitigar os impactos negativos.

\section{Degradação urbana}

Mesmo nos casos em que nāo ocorre a inundação da totalidade ou de parcela considerável das cidades localizadas nas áreas de 
influência dos reservatórios, costuma-se observar impactos sobre a infra-estrutura urbana, sobretudo em relaçāo à acessibilidade, à captaçāo de água, ao tratamento đe esgotos e aterros sanitários ou lixổes. Verificam-se, ainda, problemas em relação às atividades produtivas, especialmente extraçóes minerais e áreas hortigranjeiras, sendo que, neste último caso, como visto acima, acompanhado também pela operaçāo das UTEs. Porém, os níveis de degradação urbana nas UTEs são sensivelmente menores na etapa de implantação e moderados em sua operação, enquanto que, para as UHEs, esses níveis foram definidos como fortes na implantação e fracos na operaçáo.

\section{Patrimônio cultural}

Englobando, para efeito deste artigo, elementos tais como bens arqueológicos, históricos e paisagísticos, o patrimônio cultural revela-se de grande importância enquanto marco referencial da humanidade. Sua degradaçâo expressa a desconsideração e/ou negação do passado, da memória, da história, atitude que reflete a visão utilitarista de futuro, em profundo contraste com a noçāo de desenvolvimento harmonioso da humanidade.

Embora sejam observadas algumas interferências impostas pela operação das UTEs, designando-lhes nível moderado, estas nāo guardam correspondência com o potencial devastador das UHEs, fato que implicou a determinaçāo de valores fortes para a implantaçāo destes empreendimentos, e moderados em sua operaçẫo.

\section{DBSERVAÇÕES SOBRE A APLICAÇÃO DA MATRIZ DE IMPACTOS AMBIENTAIS PROPOSTA}

A matriz de impactos ambientais (MIA) adotada como base para o desenvolvimento deste artigo apresenta uma série de aspectos que devem ser criteriosamente avaliados. Para melhor condição de análise dos aspectos da MIA, optou-se pelo seu desdobramento em termos de implantação e de operaçăo das UHEs e UTEs. Os quadros 2 e 3 apresentam esses desdobramentos.

$\mathrm{Na}$ fase de implantaçăo, pode ser notado que é alto o grau dos impactos quando se trata de usinas hidrelétricas (UHEs). Isso pode ser percebido a partir da constatação visual de que há seis fatores negativamente fortes, sobre um total de onze. Dois dos impactos apresentam-se moderados, enquanto que três deles sâo neutros ou fracos. Acresce mencio-
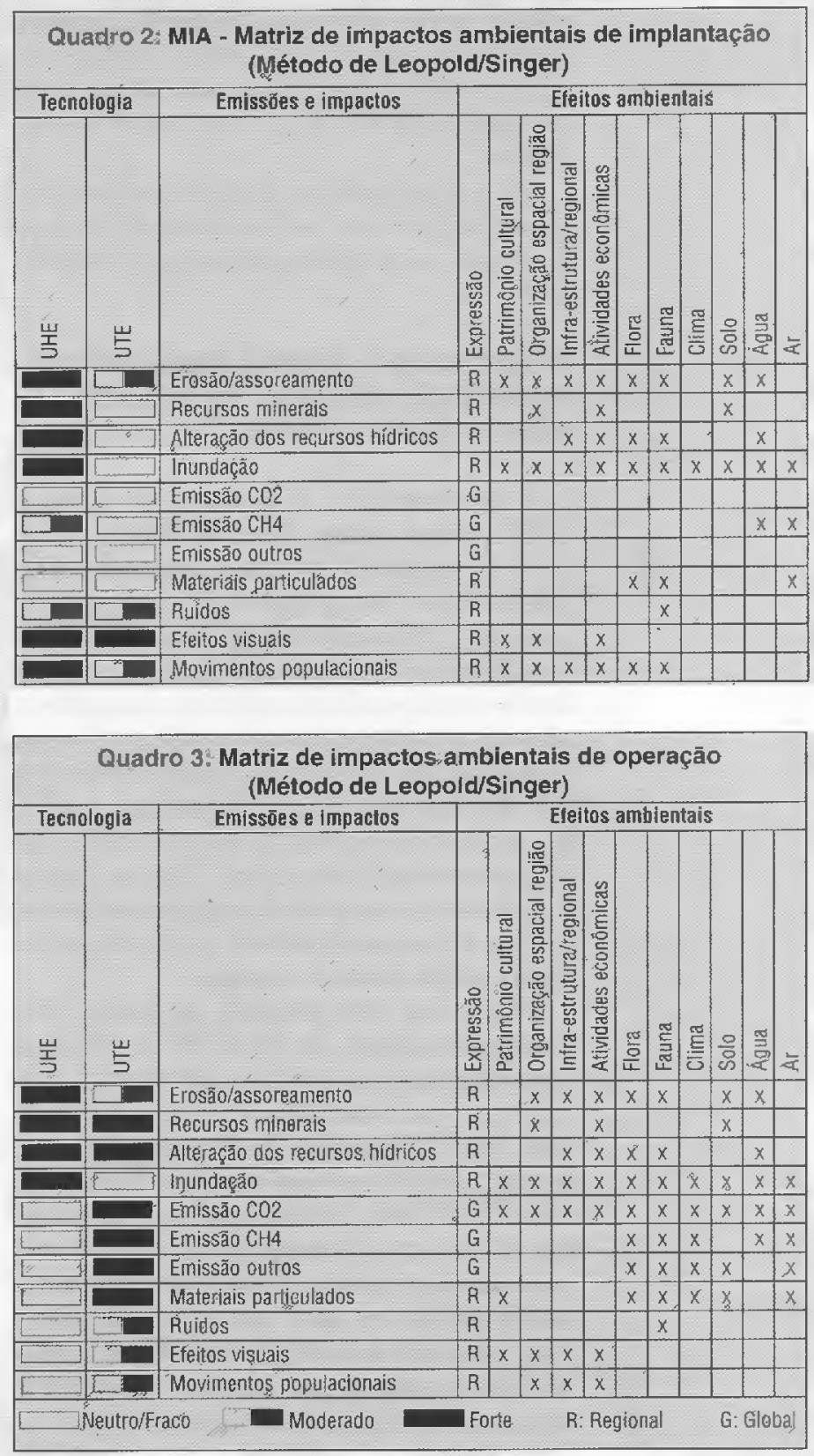

nar que aqueles seis fatores considerados apresentam um forte impacto regional.

Quanto às usinas termoelétricas (UTEs), constata-se um maior número de aspectos neutros ou fracos durante a fase de implantação. Isso leva à afirmaçāo de que, durante essa fase, as UTEs apresentam vantagens comparativas inigualáveis.

lnversamente, durante o período de operaçäo, as UHEs apresentam, segundo os parâmetros adotado na MaA, menores impactos negativos sobre o meio ambiente. $\mathrm{Ca}$ be, no entanto, destacar a pérmanência, nas duas fases, dos mesmos aspectos negativos, 
como pode ser verificado diretamente na MIA.

As UTEs apresentam como aspectos negativos aqueles três fatores apontados como de impacto global, o que não ocorre com as UHES.

Com seis aspectos de fortes impactos e quatro moderados há, durante toda a fase de operação, uma nítida desvantagem para as UTEs.

\section{CONSERVAÇÃO DE ENERGIA COMO FATOR DE PRESERVACC̃O AMBIENTAL EM SISTEMAS HIDRO E TERMOELÉTRICOS}

A implantaçāo e a operação de UHEs e UTEs podem, como descrito antes, causar danos irreparáveis ao meio ambiente. Nos países da OCDE (Organização para a Cooperação e Desenvolvimento Econômico), o crescimento econômico tem se processado sem o correspondente acréscimo energético. Mesmo considerando-se que, nesses países, tal fato deve-se também à reduçāo da produção de bens intensivos em energia, via importação, são inegáveis os avanços das ações pela conservação de energia. Nestas, buscase a alteração dos métodos e processos industriais e o desenvolvimento de novas tecnologias poupadoras de energia.

Para o ano 2015 prevê-se, no Brasil, uma potência instalada de 195 G.W $W^{6}$. A principal fonte de geração prevista é a hidrelétrica, com aproximadamente $90 \%$, e a termoelétrica, com $10 \%$. O consumo de energia previsto é de 836,7 T.W.h ${ }^{7}$, sem conservação de energia, e de 731,4 T.W.h, com implantação de medidas de conservaçāo, o que corresponde a uma expectativa de economia de 105,3 T.W.h / ano. Assim, podemos adiar determinadas obras para a geração de energia, de maneira a possibilitar o surgimento de novas tecnologias menos agressivas ao meio ambiente.

\section{ENERGIA GERADA E ÁREA INUNDADA}

6. G. W. : Giga watts, unidado de energia equivalente a $10^{\circ}$ watts hora.

7. T. W. h : Tera watts hora, unidade de energia equivalente a $10^{12}$ watts.hora.

8. CODI - COMITÊ DE DISTRIBUICAAO PROJETO 4.2.10. A questăo ambiental e a conservação de energia. Rio de Janeiro: Eletrobrás, 1993.

0 autor gostaria de agradecer ao professor Marilson Alves Gonçalves pelas revisões e sugestões. tricas Brasileiras), chegando-se ao valor de $113,4 \mathrm{~km}^{2} /$ T.W.h.

Partindo-se desse valor, conclui-se que sem a implementação de açōes de conservação de energia, haverá uma área inundada de 94.881 $\mathrm{km}^{2}$, correspondente ao consumo do ano 2015. De acordo com a meta de conservaçāo, poderá ser evitado o alagamento de uma área de $11.939 \mathrm{~km}^{2}$. O valor do índice de $113,4 \mathrm{~km} /$ T.W.h poderá sofrer variação em funçāo da revisāo das alternativas de localização das barragens e de estudos de inventário de alguns projetos previstos no plano de expansão ${ }^{8}$.

As ações de conservação de energia podem, portanto, reduzir a necessidade de novas instalaçóes, adiando-as ou reduzindo-as, e, em alguns casos, eliminando os impactos ambientais negativos. Esse adiamento de obras permitiria maior espaço de tempo para a realização de um amplo debate sobre suprimento energético.

\section{CONCLUSÃO}

Pelo exposto, pode-se concluir que a implantaçāo das grandes barragens hidrelétricas, no que se refere a processos mais comprometidos com o avanço das questões sociais, apresenta efeitos de caráter local nada desprezíveis, devendo ser, portanto, criteriosamente estudados, assim como o devem ser os empreendimentos termoelétricos.

Desse modo, argumentos tais como o número relativamente restrito de familias diretamente atingidas, frente aos amplos beneficios que a produçāo de energia elétrica proporciona, também carecem de fundamentação mais consistente. Isto porque, a esses habitantes soma-se, no caso brasileiro, cerca de um terço da população nacional colocada em posiçâo inferior à miséria. Uma situação em grande parte resultante da própria ampliação do parque gerador do país, em que o elevado endividamento nacional acarretou menores possibilidades de investimentos sociais. Tal população encontra-se excluída do acesso à energia gerada ou mesmo daquela agregada aos bens de consumo.

Nesta conclusáo, vale a pena reiterar o pensamento de que se faz necessário um debate mais profundo sobre a avaliação, em termos ambientais, dos grandes projetos hidrelétricos no Terceiro Mundo, de modo a que se relativizem, a partir do contexto regional, os impactos de nível global. $\square$

\section{9}

